\title{
Article
}

\section{The Experience of Incarcerated Mothers Living in a Correctional Institution with their Children in Ethiopia}

by

Eden Begna Gobena (Corresponding author)

$\mathrm{PhD}$ fellow

Department of Social Studies, University of Stavanger Norway

E-mail: eden.b.gobena@uis.no

Sarah Catherine Patricia Duff Hean

Professor

Department of Social Studies, University of Stavanger Norway

Faculty of Health and Social Science, Bournemouth University United Kingdom

E-mail: sarah.c.hean@uis.no

\section{Keywords:}

correctional institution, incarceration, motherhood, experience, Ethiopia, qualitative research

DOI: https://doi.org/10.31265/jcsw.v14.i2.247

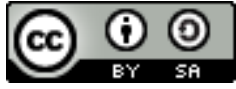

This work is licensed under a Creative Commons Attribution-ShareAlike 4.0 International License. 
Journal of Comparative Social Work 2019/2

\section{Abstract}

The needs of female inmates are different from those of their male counterparts. Little is understood of the nature of these differences, particularly for mothers who in countries such as Ethiopia may be accompanied by their children when in correctional facilities. This article is aimed at exploring these inmates' experiences of motherhood, the challenges they and their children face and their experiences of the services and support programmes available. The central research question was: 'What is the experience of incarcerated mothers living in prison with their children in Ethiopia?' A general qualitative approach was taken in the study, using in-depth interviews $(n=10)$ with incarcerated mothers who had a child living with them in a typical large, high-security Ethiopian correctional institution. Mothers questioned the perceived inclusiveness of the services available to them, with access often being denied owing to their childcare responsibilities. Participation in small business enterprises within the institution was an exception to this. They discussed the challenges facing the mother and child as a family unit, the relationship between the mother, the criminal justice system and society and finally their perceptions of the incarcerated mother as a survivor, resilient in the face of the challenges being experienced. These themes showed that incarcerated mothers perceive themselves as victims of societal discrimination, abuse and structural injustice before and after incarceration, and that correctional institution facilities left them unable to provide adequately for the physical, emotional and educational needs of their children. The role of correctional administrations, policymakers, correctional institution social workers and researchers alike in addressing the inequalities facing mothers in Ethiopian correctional institutions is discussed.

Keywords: correctional institution, incarceration, motherhood, experience, Ethiopia, qualitative research 
Journal of Comparative Social Work 2019/2

\section{Background}

Women constitute a minority in the general correctional institutions' population, although their numbers are growing at a rate far exceeding that for male incarceration in many countries (Artz \& Rotmann, 2015). This is also the case in South Africa (Dissel, 2017) and Ethiopia, with an increase from 3.3\% in 2001/02 to $4.2 \%$ in 2013/14 (World Prison Brief Report, 2017). The increase is attributed to the greater use of custodial sentences for lesser crimes such as drug offences and non-violent theft, in which women are more likely to participate (Townhead, 2008).

Women's offending and incarceration are often related to poverty and social disadvantage, and they are often unable to pay bail fees and/or the fines imposed for minor offences, thus leading to the imposition of custodial sentences (United Nations, 2014). They are usually unemployed, with low levels of education, dependent children and histories of alcohol/substance, domestic and sexual abuse (MacDonald, 2013). At the same time, they lack the support of their family and community, who stigmatize the incarceration of women more than that of their male counterparts (Baldwin, 2018).

Internationally, women's experiences of correctional institutions are acknowledged as being particularly challenging, with institutions being designed predominantly for male inmates (Coyle, 2002). Female inmates have special health needs, primarily related to reproductive and sexual health, and they often have greater family responsibilities. The type of sentencing applied, the architecture of correctional institutions, security procedures, facilities for healthcare, family contact, work and training selectively accommodate male inmates, meaning women's needs are often unaccounted for (Townhead, 2008). Although every national context will have its specific culture and challenges within its correctional system, international comparisons are of importance to acquiring an understanding of some of the universal principles facing human subjects. 
The majority of incarcerated women are mothers with at least one child under the age of 18 in Kenya (Pierre, 2016). Ethiopia is no exception to the above trend, especially since motherhood in Ethiopia is strongly viewed as a typical part of every woman's female identity and expected social role (Belaynesh, Marloes, Jac Van der K, \& Alice, 2017). For example, of the 2,474 women inmates counted in Ethiopian correctional institutions in 2010, 546 children were incarcerated alongside them (World Prison Brief Report, 2017). Allowing children to remain with their mothers during their incarceration is controversial. It is argued that keeping children with the mother acts as a motivator in terms of getting mothers to change their lives and reduce recidivism (Mignon \& Ransford, 2012). On the other hand, the needs and rights of children with regard to education, food and other basic necessities may be compromised if they remain in correctional institutions, especially in countries such as Ethiopia, where correctional institutions' resources are limited (Teferra, 2017).

The voices of female inmates remain largely absent from research into correctional institutions, making them an invisible, under-researched and critical population group (Townhead, 2008). This is particularly true of African women inmates who are mothers and are accompanied by their children in correctional institutions (Artz \& Rottman, 2015). This study addresses these shortfalls and assumptions by exploring the experiences of Ethiopian female inmates who are mothers - specifically those in a correctional centre who are accompanied by their children. Providing them with a voice offers an important and credible dimension for the decision-making required by correctional administrations, policymakers, correctional institutions' social workers and researchers alike in their contributions to service redesign, and when addressing the inequalities facing mothers in Ethiopian correctional institutions.

The study answered the central research question: 'What is the experience of incarcerated mothers living in prison with their children in Ethiopia?', as well as 
the specific research questions: 'What does motherhood look like in prison? 'What are the challenges for children who live in prison with their mothers?, and 'What programmes and services are available for mothers and their children in prison?'

\section{Methodology}

We take a critical realist approach in this study (Archer, 2003), believing that the conditions in Ethiopian correctional institutions exist independently, and that each inmate/participant interprets these conditions subjectively. This being an exploratory study, we chose not to impose a theoretical framework on the formation of the research questions and the data analysis. We take the standpoint, shared with approaches such as grounded theory (Holloway, 2005), that there is a value in allowing the themes and findings to arise directly from the participant's voice, and not to use any preconceived theoretical 'lens'. For similar reasons, a general qualitative inductive approach was taken in the study, as defended elsewhere (Thomas, 2003). The approach allowed the personal stories of Ethiopian mothers and their own interpretation of the social realities of life in correctional institutions to arise from the data provided by them, while retaining methodological flexibility within an exploratory study of this kind (Bryman, 2016).

\section{Study site}

The study was conducted in one of the six federal correctional institutions and 120 local facilities in Ethiopia. Correctional institutions and pre-trial detention centres in Ethiopia are underfunded, overcrowded and harsh, and sometimes contain life-threatening conditions for inmates in terms of health, food and hygiene (US Department of State, 2015). The rehabilitation of inmates is viewed as one of the functions undertaken by the correctional institutions, to ensure maximum crime control and prevention. The institution where this study was conducted has 14 quarters, holding a large number of males and females convicted of various crimes. The correctional institution accommodates both 
male and female inmates, though housed separately. As of February 2017, 826 female inmates resided at the correctional institution (Teferra, 2017). These inmates are held in two units - one for sentenced inmates (seven buildings) and the other for those awaiting trial (five buildings). Pregnant women and mothers accompanied by children are housed in two additional buildings, separated from the other female inmates (Teferra, 2017). The living conditions for women are less crowded, as there are fewer female inmates than male inmates. There are separate beds for each inmate, and they are provided with eating plates, glasses, blankets, showers and detergent. The maximum number of inmates held in one building is 140 , but the buildings more often house 60-70 inmates. The correctional institution also provides adult education, vocational training, recreational activities and support, and inmates run small enterprises/businesses under its rehabilitation and development programme. The food department provides three meals a day, with inmates being assigned a food allowance of 450 birr (approximately $€ 18$ ) per month. Children under the age of 18 months also receive this 450 birr allowance. Pregnant women and new mothers are given an additional privilege in the form of stoves, so they can cook the food of their choice for themselves and their children.

\section{Sample}

All incarcerated mothers and primary caregivers of their children at the correctional institution were approached for interviews, with 10 out of 37 mothers agreeing to inclusion in the study (see Table 1). 
Table 1: The demographic background of participants and their children

\begin{tabular}{|c|c|c|c|c|c|c|c|}
\hline Participant No. & Age (years) & Marital status & Education & Prior work & $\begin{array}{l}\text { Number of } \\
\text { children/Age }\end{array}$ & Charge & $\begin{array}{l}\text { Years of } \\
\text { sentence }\end{array}$ \\
\hline Participant 1 & 24 & Divorced & $\begin{array}{l}\text { No formal } \\
\text { education }\end{array}$ & Housewife & 1 , aged 3 & Child neglect & 3 \\
\hline Participant 2 & 25 & Separated & Elementary & Minor retail trade & 1, aged 2 & Theft & 4 \\
\hline Participant 3 & 26 & Divorced & High school & Minor retail trade & 1 , aged 5 & Theft & 2 \\
\hline Participant 4 & 34 & Divorced & Elementary & Merchant & 1,11 years & Assault & 2 \\
\hline Participant 5 & 25 & Married & Elementary & Merchant & 2,3 and 5 years & Theft & 8 \\
\hline Participant 6 & 42 & Married & $\begin{array}{l}\text { No formal } \\
\text { education }\end{array}$ & Housewife & $\begin{array}{l}5,3,8,10,15 \& 17 \\
\text { years }\end{array}$ & Attempted murder & 9 \\
\hline Participant 7 & 25 & Separated & $\begin{array}{l}\text { No formal } \\
\text { education }\end{array}$ & Merchant & 1,3 years & Physical abuse & 3 \\
\hline Participant 8 & 21 & Separated & High school & Waiter at café & 1,2 years & Theft & 4 \\
\hline Participant 9 & 28 & Married & Elementary & Minor retail trade & 1,1 year & Physical abuse & 8 \\
\hline Participant 10 & 21 & Separated & Elementary & Housemaid & 1, 2 months & Murder attempt & $\begin{array}{l}\text { Custody } \\
\text { awaiting tria }\end{array}$ \\
\hline
\end{tabular}


Individual in-depth interviews were conducted with the aid of an interview guide (Bryman, 2016). Because of the institution's regulations and security restrictions, participants were interviewed individually in an office inside the institution, accompanied by a guard. As audio recording of the interviews was not permitted, so detailed manual notes were taken, focusing on recording the mothers' entire statements. The interviews lasted approximately one hour for each participant, and were conducted in their local language. Quotations were then translated into English for the reports, and the transcripts of each interview were crosschecked with the participants (Bryman, 2016).

\section{Analysis}

An inductive thematic analysis was conducted, following methods recommended by Graneheim and Lundman (2004). This involved familiarization, the identification of meaning units (usually a sentence or groups of sentences that capture a single concept or idea) and assigning each meaning unit a brief heading, summarizing its meaning in an open coding process. These codes were grouped into higher-level categories, clearly rationalizing the membership of each one, and constantly comparing them. Sub-themes and themes were created from the categories in a process of abstraction. In order to confirm the trustworthiness of the categorization and abstraction process, the initial analysis, the creation of categories and themes and an overall description of each theme were shared with the authors (Bryman, 2016). Nvivo software (11.4.2) was used to assist in the analysis and code the data.

\section{Ethical considerations and limitations}

Ethical clearance for the study was obtained from the Norwegian Privacy Ombudsman for Research and Norwegian Social Science Data Services (NSD), and separately from the Ethiopian Federal Correctional Administration office and management of the study site. Consent to participate was obtained verbally because of the low literacy levels of the study population, and they were informed about the confidentiality and anonymity of their information.

Information was gathered from mothers, who as a result of being in the correctional institution were vulnerable and had a lower power status. The correctional 
administration and guards initiated the first contact with the mothers; hence, inmates may either have felt obliged to participate or may have presented an overly positive view based on their lower status. The presence of an officer during the interviews was a requirement of the correctional institution. This may have impacted the participants' ability to comfortably express their stories and freely participate. Thus, there may well be stories that have not been told, but prison-based research must reach a compromise between collecting data with some acknowledged limitations because of the secure and controlled environment in which collection is performed versus not collecting any data at all.

To ensure mothers were not coerced into participating in the study by the guards or administration, the researcher gave the participant a thorough introduction to the study, its purpose and its voluntary nature before the interview began. Attempts were also made to create a safe and relaxed environment during the interviews, so mothers felt safe enough to share their experiences as freely as possible, despite the presence of the guard. Through an emphasis on their similar ages, gender and nationality, participants were given the option of stopping the interview at any time and the opportunity to build a close rapport with the researcher, thereby underplaying any educational and class differences as far as possible. The information was gathered in Amharic (the working language in Ethiopia), whereas the analysis and reports were in English. The researcher was Ethiopian, and a native speaker of Amharic, enabling her to minimize any cultural and linguistic misrepresentations when collecting and reporting data in different languages (Kirkpatrick \& Van Teijlingen, 2009).

\section{Results}

Four themes emerged from mothers' descriptions of their experiences in a correctional institution. They related to their perceptions of the inclusiveness of services available to mothers, the challenges facing the family unit within the correctional institution, the relationship of mothers with the wider society and the justice system, and finally their perceptions of themselves as survivors within this difficult context. 
Inclusiveness of services in the correctional institution

This theme describes how mothers believed themselves to be excluded from the support available to other inmates. Firstly, mothers describe financial exclusion; they talk of how the correctional institution provides financial support in the form of 450 Ethiopian birr for each child, but believe the money is not sufficient to adequately support them. More importantly, this allowance stops when the child reaches the age of 18 months, with the mothers then expected to take care of all their children's needs on their own allowance alone.

Secondly, mothers described a range of programmes made available by way of inmate services, such as education and vocational training programmes. However, they spoke of limited consideration being given to the needs of mothers with children in terms of how they can access these services.

'There is primary education and vocational training for all inmates, but it is not convenient for a mother' (mother aged 21).

These programmes were not easily accessible to mothers, primarily because of the institution's regulations, prohibiting children from going with their mothers to classes or training sites. This means the mothers cannot attend the training, as they do not have childcare alternatives.

The children should not move from the place they are assigned, and we cannot leave our children alone ... this is the regulation of the institution ... children cannot go to the class or the training place, and we have to be with them all the time. It is like choosing between your child and education. (mother aged 25)

In contrast to education and training, mothers reported how they had easier access, and were included in the micro-enterprise programmes.

'I think from the other programmes here that these small enterprises are more inclusive of us'. (mother aged 26)

The correctional institution sought to rehabilitate and support inmates in the financial organization of micro-enterprises. The mothers describe micro-enterprises as a source of income that helps provide the means to provide their children with food, clothing and sanitary materials. They also believe small enterprises benefit the wider community of inmates, providing services for fellow inmates and staff. 
The challenges for the family unit in a correctional institution

This theme describes the challenges for the family unit when mother and child are together in a correctional institution. Firstly, mothers mentioned the difficult time they had during pregnancy and childbirth in the correctional institution. Access to water and medical care, as well as food provision in the correctional institution, were deemed insufficient and of poor quality.

'Having a child is a big phenomenon in a woman's life and experiencing this big thing in this harsh environment with no one to take care of you is so painful' (mother aged 25).

'I had my daughter here, and I had a tough time at the moment' (mother aged 28). In terms of their family outside, mothers reported that being in the institution created a distance between them and any children they may have left outside. They speak of the shame they feel in front of their families on the outside, with several mothers reporting not wanting their families to know about their incarceration.

'I do not want my family to know about my situation' (mother aged 21).

They believed that the children with them in the correctional institution were also suffering, and they blamed themselves for this, describing them as victims of their incarceration. They report their children having physical problems because of poor facilities, and that they are denied access to education, proper medical care, nutrition and a space to play in the correctional institution. The mother and other women offenders were also informally teaching children of school age.

'Here, the children do not get an education' (mother aged 26 with a five-year-old child).

'There is no special food for our children' (mother aged 25 with a three-year-old child).

'Even with our children, they do not get special medical treatment ... if they get sick, they are usually treated like adults unless the sickness is severe' (mother aged 25 with a two-year-old child).

In the mothers' opinion, their children have mental health and behavioural problems, exhibiting behavioural changes and aggressiveness after being brought to the correctional institution. The mothers expressed concern that a high level of contact with other inmates would lead to their children developing criminal behaviours. Most of the mothers expressed the pain they feel at not being able to provide for the needs of their children, whether they lived within or outside the correctional institution. 
Mothers' relationship with society and the justice system

This theme describes the mothers' perceptions of their relationship with the justice system, the other inmates and the community they came from. With the exception of two participants, all the mothers interviewed were divorced or separated, and they did not receive any positive support for their child's needs from their partners. One mother stated that she had no confidence in claiming her right to receive support from the child's father because of the lack of a marriage certificate, with others describing incidences of physical domestic abuse.

'Because we did not register our marriage in the first place, I do not have any right to claim his support legally, plus I am here now' (mother age 26).

They feel they are discriminated against within society because of a lack of legal knowledge about the rights of women, and feel they are the victims of structural injustices on the outside. For example, one mother reported that a man raped her only daughter, but she could not get a proper investigation or answers from the police or the court.

The reason I got imprisoned was because of my child. A young man raped my daughter last year, and I reported the case to the police but it didn't get a proper investigation. At that time I was so hurt that I was about to lose my mind because she is my only child that I raised by myself. (mother aged 34, daughter aged 11)

This injustice and discrimination led her to criminality. She continued speaking of her frustration and her decision to attack the man:

'After I realized that there was no appropriate response from the police and when my neighbours sided with the criminal, I attacked the guy physically, and I got arrested for assault.'

They describe their relationships with their home community as broken, their neighbours having stopped contacting them upon incarceration and very few getting regular visits from their family or relatives. They fear that the discrimination may affect them after finishing their sentences, e.g., when attempting to get a job or reintegrate with society.

In contrast, participants reported that they had a good relationship with other inmates. They reported that other female inmates understood their challenges as mothers, and that they supported each other during childbirth and child-rearing in the correctional institution. However, one mother mentioned that relationships with the other inmates were not always entirely healthy, and that there were times when some arguments 
and bad issues had arisen. However, she said that overall the relationships were good and smooth.

\section{Mothers being a survivor}

This theme was connected with the notion of the personal energy, strength and enthusiasm mothers felt despite the many challenges they faced, and the fact that they had no one on the outside to support them. Mothers described themselves as the primary and sole caretakers of their children - only two interviewees were married and received support from their husbands. All the other participants were either divorced or separated from their partners, and did not get any support or visits. The mothers reported that their families were poor and unable to support themselves or their children. Two mothers were housewives, while the rest were engaged in lowincome jobs before incarceration. Five mothers identified themselves as financially poor and came from low-income families, which left them as the sole caretaker. Despite these challenges and the lack of support, mothers describe their courage in facing the various adversities. They describe a spirit of survival, resilience and the strength to go forward, overcome the adversities and eventually shoulder their responsibility as a mother with a positive impact on their child:

One thing I believe even if I am here I can impact my child positively as I am the one who stays with her all the time while she is here ... For example, me, even if there is no education for our children, I teach her the alphabet, how to speak and other moral values and norms as much as I can. Whenever she does something unacceptable, I correct her and teach her what is right and wrong. (mother aged 25, child aged 3)

Having their children with them in the correctional institution contributed to the mothers' resilience. One mother linked her having her child with her in the institution as an opportunity to spend enough time with her baby girl that she would not have otherwise had:

Here, I am able to give my full time for my child. As there is nowhere we can go, all of us mothers spend our full time with our children. I am happy about that ... before I came here, I was busy with work and making ends meet. I had my child after I came here and I can take care of her as much as I can. If I were not incarcerated, I would not be able to give this much time for my child ... as you know life is so hard in this country; unless you work hard it is difficult to continue with life. Being here helped me to give all the motherly love and time for my child. (mother aged 21, child aged 2) 


\section{Discussion}

The exploratory study described in this paper has presented some of the experiences of incarcerated mothers living with their children in an Ethiopian correctional institution. It contributes to what is only a small body of work, particularly in an African context, putting the voice of women offenders, and especially mothers, at the centre of inquiry (Artz \& Rotmann, 2015). It shows motherhood in Ethiopian correctional institutions to be challenging, complex and multifaceted. Such complexity can be understood as a series of interrelating personal, familial, correctional institution and societal systems (Healey, 2014). Each system is a source of tension and challenge, providing a different starting point or trigger with which to develop correctional institution practice in the future (Engeström \& Sannino, 2011), thereby improving the fit between these mothers and the environment in which they find themselves.

\section{Mothers' lack of choice regarding alternative care of their children}

As is the situation in other countries, e.g. Cameroon and South Africa (Dissel, 2017; Linonge-Fontebo \& Rabe, 2015), mothers rarely receive support for childcare when incarcerated in Ethiopian correctional institutions, either from the male parent or the wider family. There is therefore little choice but for children to remain with the mother for the duration of her sentence, and far longer than the age of 18 months.

Alternatively, the funding policy governing the allocation of rations to mothers should be reconsidered, so as to address the reality of children remaining with their mother beyond the aforementioned age. Although not a choice, there are advantages in keeping the child with the mother, separation being shown to have negative outcomes for the child, e.g., delinquency, psychopathology and antisocial behaviour (Murray \& Murray, 2010).

Isolation of the mother: Work towards rebuilding her links with her community and family

Mothers spoke of what society considered to be a good mother, and believed incarceration had tarnished this identity for them. They worried about their relationship with their home community and the discrimination they would face upon release. In a patriarchal and traditional society such as Ethiopia, their perceived failure as mothers may make this discrimination particularly marked, although the loss of the identity of a 'good mother' is reported in other national contexts (e.g. 
England and Wales, Baldwin, 2018). Although the family dynamics for many of these women may be similar to those for many mothers on the outside (in terms of lone parenthood and single mothers caring for their children in African society) (e.g. South Africa, Artz \& Rotmann, 2015), the key issue here is the fact that the extended family and community links that compensate for the breakdown of a two-parent family unit (aunts, grandparents, friends) are denied to mothers in prison owing to their marginalization from their wider family and community. Hence, there is a need to combat stigmatization of this population group, and for authorities to seek to actively rebuild links between the mother and her community and family.

Although women discussed the public stigma that is the reaction that the general population has to incarcerated mothers (Corrigan \& Watson, 2002), they did not reflect on any experiencing of stigma in the correctional institution, whether based on their status as inmates and mothers or on the crime or civil status, whether exercised by the correctional institution staff or by other inmates. However, the sensitivity of this situation, bearing in mind their current situation living in the correctional institution, and the presence of the officer in the interview, make this difficult, and interviews with women after release may be a better source for this information.

\section{Pain and guilt: Wherever children are}

But regardless of where the child is kept, mothers in this Ethiopian correctional institution speak of their pain and guilt in being unable to meet their maternal responsibilities. They feel this if they are separated from their children on the outside, as well as if the children remain with them, and when describing the correctional institution environment in which their children are growing up without adequate health services, food, formal education and proper accommodation, in addition to experiencing potentially antisocial influences. These feelings of shame, guilt and frustration are shared with incarcerated mothers in Zambia (Africa) (Malambo, 2016), as well as western countries such as Australia and Romania (Müller-Fabian, 2015; Stanley \& Byrne, 2000). This similarity in the mothers' experience in correctional institutions in different parts of the world shows the universal principles and challenges facing incarcerated mothers. 
A penal system that has not kept up with the reality of the mothers' predicament Mothers talk of tension within the correctional institution between the regulations determining how money is distributed between inmates and the reality of what mothers and children need to sustain themselves when incarcerated. Mothers find themselves in a double bind (Engeström \& Sannino, 2011), not having any alternative care because of their isolation and experiencing a low status in the wider familial and social systems, as well as suffering from limited resources within the institution if the child remains with them.

Although mothers understand that financial allowances are being made within the system for pregnant and breastfeeding mothers, female inmates describe the reality of having to share rations with their children after they reach the age of 18 months. They feel that this puts them at risk of not receiving adequate nutrition for both themselves and their babies. This deficit reflects reports elsewhere, in which the infrastructure and legislative framework of contemporary African penal systems are described as being largely unchanged from the systems introduced in the colonial period (Dissel, 2017), and which may not have been adapted to the reality of women being in correctional institutions with their children (e.g. Cameroon, Linonge-Fontebo \& Rabe, 2015). Even though correctional institutions in Africa offer a range of facilities such as healthcare services and educational programmes, institutions across the continent remain under-resourced and understaffed (Dissel, 2017). Increasing rates of incarceration and lengths of sentences puts ever-increasing pressure on these systems, which are already being criticized for their unacceptable levels of disease, violence, death, violation of human rights and overcrowding (Malambo, 2016). The ability of these systems to then fund and manage mothers and children within these institutions is therefore limited (Linonge-Fontebo \& Rabe, 2015).

The United Nations Rules on for the Treatment of Women Prisoners and NonCustodial Sanctions Measures for Women Offenders, 'The Bangkok Rules' (United Nations, 2011), clearly state that children in a correctional institution with their mother (or father) should never be treated like inmates, and that all their needs should be fulfilled and met. The Constitution of the Federal Democratic Republic of Ethiopia (1995) similarly recognizes international human rights standards, including those of the rights of the children and women. However, because of the limited resources 
available to the correctional institutions, there are some difficulties in implementing these standards.

\section{Rehabilitation programmes have not adapted to mothers' needs}

Over the past two decades, Ethiopian correctional institutions' policies, as in European contexts, have increasingly focused on restorative justice and rehabilitation processes (Messele, 2017). Yet, there is a direct conflict within the correctional institutional system between regulations governing access to these formal support programmes (e.g. education and vocational training) and a mother's role, and her responsibilities for her children. This conflict means that most mothers are not able to participate; thus, they are excluded from rehabilitation programmes for inmates as a key strategy in reducing recidivism rates and preparing offenders to re-enter society (Dissel, 2017). This constitutes a severe inequality in terms of correctional institution service provision and future opportunities for these mothers, despite efforts to the contrary embodied in current policy and regulations that legislate the rights for mothers and children (e.g. the Council of Ministers' Regulations on the Treatment of Federal Prisoners, 2007). The correctional administration should pay greater consideration to the needs of these mothers, either allowing children to attend programmes with their mother or providing childcare or cooperative childcare among fellow female inmates.

The predominant theory behind correctional institutions' rehabilitation programmes, e.g., those employed in Ethiopia, is the Risk-Need-Responsivity (RNR) model (Andrews, Bonta, \& Wormith, 2011) - a theoretical tool developed from a synthesis of the empirical findings regarding what works in rehabilitation and what does not. Its purpose is to guide professional decision-making related to the risk posed by the inmates, and how their needs can be addressed in a way that is specific to them as individuals. In brief, the Risk $(\mathrm{R})$ principle proposes that inmates at a higher risk of recidivism will benefit most from rehabilitation interventions, and hence they should be provided with limited resources, rather than lower-risk inmates. Mothers did not explore their own risk or other reasons for them not attending programmes, other than their children, although there may have been entry requirements (such a level of risk) that they were not themselves aware of. 
The Need principle $(\mathrm{N})$ suggests that recidivism is associated with basic risk factors linked to so-called criminogenic needs. Low educational attainment, substance misuse and antisocial networks are some of the eight main factors that might lead to recidivism in the future (Skeem \& Petersen, 2011). If this issue is addressed, inmates may be protected against future criminal behaviour. Rehabilitation models underpinned by the RNR model therefore seek to ameliorate these criminogenic needs through education and training programmes or substance-abuse treatment. The case-study site offered a range of such programmes to mothers. Training programmes and participation in the microenterprises were discussed as particular ways in which key skills and competencies could be developed.

Finally, the Responsivity principle $(R)$ states that rehabilitation programmes should take inmates' individual characteristics into account, addressing, for example, their learning style, level of motivation and personal and interpersonal circumstances (Andrews et al., 2011). Discussions with mothers showed that the formal programmes offered at this case-study site had not taken into account mothers' personal circumstances in their programme design. This situation typifies a system in which rehabilitation programmes have largely been designed for the male majority of inmates and their individual needs. It shows the need to take more heed of service users' viewpoints in correctional institutions' service design, especially when the rehabilitation of minority groups is being planned.

\section{Small enterprises are more inclusive of mothers and are strength-based}

In contrast to formal programmes employed within the case-study site, the small-enterprise services part of the rehabilitation programme is more inclusive, and is more beneficial for mothers and the general correctional institution community. Inmates are encouraged, and choose to form associations based on their interests, existing skills and job training, and work in collaboration to help facilitate their work. There are seven associations in which women inmates work in collaboration with each other, with the activities including restaurants, handmade clothing, embroidery, small-scale agricultural work, beauty salons and preparing fresh fruit smoothies for sale. These services/products are sold to fellow inmates and other correctional institution staff. The enterprises' profits are saved up in the inmates' bank accounts. The participants reported that these enterprises are more inclusive of mothers, 
because they can work based on their skills, while keeping their children with them. Unlike the RNR model, which focuses on the offender's deficit, the microenterprise approach is more in tune with the Good Life Model of Rehabilitation (Ward, Yetes, \& Willis, 2012), which involves an appreciative or positive focus on what mothers can do, rather than a negative focus on their shortcomings and needs (e.g. educational deficits). Similarly, it is in keeping with a 'strengths' perspective, whereby individual well-being and the reduction of social problems is achieved by building on mothers' own resources (i.e. capabilities, skills, assets) (Healy, 2014). Focusing on the mothers' strengths does not ignore the existence of criminogenic needs, but instead chooses to prioritize the contributions they have to offer (Gray, 2011). Engaging a mother in various activities gives her hope, the confidence to be a better person and someone who is able to support herself and her children outside a correctional institution, free of future criminal behaviours.

Mothers in correctional institutions need better knowledge of their rights and those of their children

Mothers mentioned a lack of knowledge of their rights regarding the receipt of support from partners, with one mother stating that she could not claim child support from the father of the child because they did not legally register their marriage. However, Ethiopian Family Law (2000) states that: 'The man and the woman engaged in an irregular union shall be jointly and severally liable for all debts incurred for their maintenance, or for the maintenance of their children born of such union.' This lack of knowledge may be related to the mothers' educational background and economic status (only two of them finished high school, three of them were illiterate and the remaining five participants only attended primary school). These are not uncommon demographic characteristics in this population group, and they are seen in other national contexts such as Romania and South Africa (Müller-Fabian, 2015; Artz \& Rotmann, 2015). Overall, in the correctional institution system, a greater consideration could be given to educating women in their rights as mothers within the correctional institution, as well as within society. 
Taking into account mothers' social disadvantage and family responsibility during sentencing

Mothers at this Ethiopian correctional institution have a strained relationship with both society and the justice system. They report themselves as being disadvantaged and often victims of abuse and injustice before incarceration. Although these reports will be subject to self-presentational biases, there is a need to explore the degree to which the Ethiopian and international judicial or legal systems deal with mothers based on their childcare responsibilities and social disadvantage. Similar studies in Africa and Europe (Artz \& Rotmann, 2015; MacDonald, 2013) show that large numbers of female prisoners have experienced abuse and injustices within society, and this situation can be one of the reasons for women's offending behaviour. The greater increases in the rate of women's incarceration in some countries than those for men, and the higher proportion of non-violent crimes in the female correctional institution population, as well as the impact on the family system, suggest that a more holistic view is needed when handing down sentences. Decision-making should go beyond simple punishment of the individual, retribution, deterrence and public security.

\section{Being a survivor}

Mothers discuss their feelings of being a survivor within the correctional institution system as something largely driven by their need to care for their children. Their children gave them the courage and motivation to move forward, and they showed a willingness to sacrifice whatever was necessary to raise their children in the correctional institution environment. Although they see themselves as survivors, they say little about how they have achieved this role. Future research is now required, so as to better explore the social agency of mother and child within this wider correctional institution system, building on the descriptions we have presented here and exploring the strategic moves mothers and their children might make to adapt toand manage within the correctional institution structures that surround them.

Emphasizing the resilience of mothers and rewarding their maternal responsibilities is in keeping with a strength-based social-work perspective (Healy, 2014). It should thus be recommended that staff at correctional institutions working with mothers promote this strength-based approach, which acknowledges mothers' value, their 
positive contribution to their children's upbringing, and their role as mothers, as well as workers contributing to the larger society. The mothers could be praised for not giving up on their children, and for raising their children and creating a positive impact, even when in a correctional institution. In fact, enabling contact and parental responsibility for the child, whether the child is on the inside or outside, has been shown to facilitate positive re-entry plans for women and reduce their recidivism rates (e.g. the USA, Mignon \& Ransford, 2012).

\section{Conclusion}

The reality in Ethiopian correctional institutions is that many children remain with their mothers for the duration of their sentence. While the child and mother may gain from this continued contact, the challenges as voiced here by incarcerated mothers are complex, and mothers feel pain and guilt about their maternal responsibilities, regardless of whether their children are with them or not. Some of these challenges are related to the way the correctional institution system has been designed, ignoring or failing to adapt to the mothers' specific constraints. Correctional institutions need to adapt their rehabilitation programmes so as to better suit mothers, through acknowledging and catering for their child-care responsibilities and focusing on their strengths and competencies. Mothers also need to be educated in terms of their rights in and out of correctional institutions, and active efforts are necessary to reconnect them with their communities and families, so they will be able to support the mothers and their children both during and after their sentences. The wider position of these women within the community and society in general means mothers and their children are greatly disadvantaged, which should be taken into account when sentencing mothers to custodial sentences in the first place. 


\section{References}

Andrews, D. A., Bonta, J., \& Wormith, J. S. (2011). The Risk-Need-Responsivity (RNR) Model: Does adding the good lives model contribute to effective crime prevention? Criminal Justice and Behavior, 38(7), 735-755.

https://doi.org/10.1177/0093854811406356

Archer, M. (2003). Structure, Agency and the Internal Conversation. New York: Cambridge University Press. https://doi.org/10.1017/CBO9781139087315

Artz, L., \& Rotmann, B. (2015). Taking 'A Count' of Women in Prison, Agenda, 29(4), 3-13. https://doi.org/10.1080/10130950.2015.1129091

Baldwin, L. (2018). Motherhood disrupted: Reflections of post-prison mothers. Emotion, Space and Society, 26, 49-56. https://doi.org/10.1016/j.emospa.2017.02.002

Belaynesh, T., Marloes, V. E., Jac Van der K., \& Alice, S. (2017). The grace of motherhood: Disabled women contending with societal denial of intimacy, pregnancy, and motherhood in Ethiopia, Disability \& Society, 32(10), 15101533. https://doi.org/10.1080/09687599.2017.1361385

Bryman, A. (2016). Social Research Methods. (5th ed). Oxford: Oxford University Press.

Corrigan, P. W., \& Watson, A. C. (2002). Understanding the impact of stigma on people with mental illness. World psychiatry: Official journal of the World Psychiatric Association (WPA), 1(1), 16-20.

Coyle, A. (2002). A Human Rights Approach to Prison Management: Handbook for prison staff: London: International Centre for Prison Studies.

Dissel, A. (2007). Rehabilitation and Reintegration in African Prisons. Human Rights in African Prisons, HSRC Press: Cape Town, 2007, 155-176.

Engeström, Y., \& Sannino, A. (2011) Discursive manifestations of contradictions in organizational change efforts: A methodological framework, Journal of Organizational Change Management, 24(3), 368387, https://doi.org/10.1108/09534811111132758.

Graneheim, U., \& Lundman, B. (2004). Qualitative content analysis in nursing research: Concepts, procedures, and measures to achieve trustworthiness. Nurse Education Today, 24(2), 105-112. https://doi.org/10.1016/j.nedt.2003.10.001 
Gray, M. (2011). Back to Basics: A Critique of the Strengths Perspective in Social Work. Families in Society: The Journal of Contemporary Social Services, 92(1), 5-11. https://doi.org/10.1606/1044-3894.4054

Healy, K. (2014). Social Work Theories in Context. (2nd ed.). UK: Palgrave Macmillan. https://doi.org/10.1007/978-1-137-02425-1

Holloway, I. (2005). Qualitative Research in Health Care, Maidenhead, UK: Open University Press.

Kelbisow, S. A. (2006). The Situation of Children of Imprisoned Mothers: The Case of Addis Ababa Prison, Addis Ababa: Addis Ababa University.

Kirkpatrick, P., \& van Teijlingen, E. (2009). Lost in translation: Reflecting on a model to reduce translation and interpretation bias. The Open Nursing Journal, 3, 25-32. https://doi.org/10.2174/1874434600903010025

Linonge-Fontebo, H. N., \& Rabe. M. (2015). Mothers in Cameroonian Prisons:

Pregnancy, Childbearing and Caring for Young Children. African Studies, 74(3), 290-309. https://doi.org/10.1080/00020184.2015.1068000.

MacDonald, M. (2013). Women Prisoners, Mental Health, Violence, and Abuse. International Journal of Law and Psychiatry, 36(3-4), 293-303. https://doi.org/10.1016/j.ijp.2013.04.014

Malambo, O. (2016). The welfare of children living with incarcerated mothers in selected prisons of Zambia, Lusaka: University of Zambia.

Messele, B. E. (2017). A Critical Review on the Ethiopian Criminal Justice Policy; With Special Emphasis on the Prison Policy: Bahir Dar University, School of Law (Accessed on January 22, 2018). Retrieved from file:///Users/eddybegna/Downloads/Prison Policy Review.pdf.

Mignon, S. I., \& Ransford, P. (2012). Mothers in Prison: Maintaining Connections with Children. Social Work in Public Health, 27(1-2), 69-88. https://doi.org/10.1080/19371918.2012.630965

Müller-Fabian, A. (2015). Main Characteristics of Inmate Mothers, Emphasized on their Psycho-socio-educational status. Procedia - Social and Behavioral Sciences, 209(July), 344-350. https://doi.org/10.1016/j.sbspro.2015.11.247 Murray, J., \& Murray, L. (2010). Parental Incarceration, Attachment and Child Psychopathology: Attachment \& Human Development, 12(4), 289-309. https://doi.org/10.1080/14751790903416889 
Pierre, E. (2016). Mental Health Rights of Incarcerated Mothers who are Accompanied by their Children in a Kenyan Prison, Gothenburg: University of Gothenburg.

Skeem, J., \& Peterson, J. (2011). "Major Risk Factors for Recidivism Among Offenders with Mental Illness. Report prepared for the Council of State Governments (CSG)." (Accessed November 16, 2016). Retrieved from http://riskreduction.soceco.uci.edu/index.php/publications-all/published- riskassessments/.

Stanley, E., \& Byrne, S. (2000). Mothers in Prison: Coping with Separation from Children. Australian Institute of Criminology

Teferra, E. (2017). Challenges of Incarcerated Children, Addis Abba: Addis Ababa University.

The Constitution of the Federal Democratic Republic of Ethiopia. (1995).

Proclamation No.1/1995: Addis Ababa. (Accessed on April 25, 2018).

Retrieved from http://www.wipo.int/edocs/lexdocs/laws/en/et/et007en.pdf.

The Council of Ministers Regulations on the Treatment of Federal Prisoners (2007).

The Council of Ministers: Addis Ababa, Ethiopia (Accessed on March 11, 2018). Retrieved from https://chilot.files.wordpress.com/2011/01/reg-no-138treatment-of-federal-prisoners.pdf.

The Federal Democratic Republic of Ethiopia Revised Family Code (2000).

Proclamation No.213/2000: Addis Ababa (Accessed on April 25, 2018).

Retrieved from http://www.refworld.org/pdfid/4c0ccc052.pdf.

Thomas, R. D. (2003). A general inductive approach for qualitative data analysis.

School of Population Health, University of Auckland: New Zealand (Accessed on April 25, 2019). Retrieved from

http://www.frankumstein.com/PDF/Psychology/Inductive\%20Content\%20Analy sis.pdf.

Townhead, M. B. (2008). Women in prison: A commentary on the UN Standard Minimum Rules for the Treatment of Prisoners. Human Rights \& Refugees Publications, 1(2), 67-78.

United Nations (2011). United Nations Rules for the Treatment of Women Prisoners and Non-custodial Measures for Women Offenders (the Bangkok Rules), Crime prevention and criminal justice: Bangkok, Thailand (Accessed on 
October 8, 2018). Retrieved from https://www.unodc.org/documents/justiceand-prison-reform/Bangkok_Rules_ENG_22032015.pdf.

United Nations (2014). Handbook on women and Imprisonment (2nd ed.). New York: United Nations Publication.

US Department of State (2015). Human Rights Report Ethiopia (Accessed on February 19, 2018). Retrieved from https://www.state.gov/documents/organization/252893.pdf.

Ward, T., Yates, P.M., \& Willis, G. (2012). The Good Lives Model and the Risk Need Responsivity Model: A Critical Response to Andrews, Bonta, and Wormith (2011). Criminal Justice and Behavior, 39, 94 -110. https://doi.org/10.1177/0093854811426085

World Prison Brief Report (2017). Institute for criminal policy research, 4th edition. University of London (Accessed on April 25, 2019). Retrieved from http://www.prisonstudies.org/news/world-female-imprisonment-list-fourthedition. 